\title{
Performance Analysis of Actual Step and Mesh Voltage of Substation Grounding System with the variation of Length and Number of Ground Rod
}

\author{
Shwe Myint \\ Electrical Power Engineering Department, \\ Mandalay Technological University, \\ Mandalay, Myanmar
}

\author{
Yan Aung Oo \\ Electrical Power Engineering Department, \\ Mandalay Technological University, \\ Mandalay, Myanmar
}

\begin{abstract}
The performance of Earthing grid system is very important to ensure the human and protective devices in safe environment. Actual Step and Mesh voltage of a substation must keep under the maximum allowable limits under fault condition. Ground potential rise, GPR is greatly influence on actual step and mesh voltage of substation grounding system. Ground potential rise also mainly depends on the length and numbers of ground rods and grid spacing. This paper presents performance analysis of actual step and mesh voltages of a substation grounding system under the variance of length and number of ground rods. The performance result is also carried out by using current injection method and with the help of MULTISIM simulation software.
\end{abstract}

Key words: Actual touch and step voltage, current injection method, earth rod, earthling grid design, grid resistance, Ground Potential Rise, MULTISIM simulation software.

\section{INTRODUCTION}

The main objectives of a substation grounding system is to provide a path that carry electric currents into the earth under normal and fault conditions without exceeding any operating and equipment limits or adversely affecting continuity of service and to assure that a person in the vicinity of grounded facilities is not exposed to the danger of critical electric shock. So, it is necessary to calculate the safety step and touch voltage level for the person who works in the vicinity of grounded facilities in normal condition. Under normal condition, i.e., the horizontal elements do not have any failures, the touch and step voltages, shown in figure 1 , will not be dangerous for staff or equipment that stand on the top stratum of soil. But, during abnormal situations such as insulation failures of equipment, lightening strokes and etc., high currents flows through the grounding grid. In this situations a very high voltage levels of actual step and touch voltage will be introduced and the environment will not safe anymore. The highest values of voltage rise will be on the edge elements of the grounding device [4]. The value of actual mesh voltage and step voltage must less than tolerable touch and step voltage even under the fault condition. Therefore, it is also very important to design the earthing grid system so that the actual step and touch voltage level would be maintained within the allowable limits. The actual step and touch voltage level mainly depend on the ground potential rise, GPR. The more the GPR rise, the higher the actual step and touch voltage level. The major parameters of the earthing grid design are soil resistivity, spacing and size of horizontal grid and length and number of vertical earth rods. The variance of length and number of vertical earth rods under the uniform soil resistivity will greatly affect the value of ground potential rise. The main purpose of this paper is to choose the most safety earthing grid design over the three following cases: a substation-

(i) with $38 \times 10 \mathrm{~m}$ ground rods earthing system,

(ii) with $76 \times 5 \mathrm{~m}$ ground rods earthing system and

(iii)with 126x3 m ground rods earthing system under the same uniform soil area. 




Figure 1: Touch and Step voltage Exposure

\section{BUILDING EARTH GRID MODEL}

Since grounding grid is mainly composed of horizontal earth electrodes and vertical earth rods, it is needed to make a circuit model that represents the horizontal and vertical element. All the horizontal and vertical elements shown in figure 2 represent not only self-resistance of conductors itself (steel, copper, copper clad etc.) but also lumped-resistances to earth of the buried in soil conductors. It consists of three parts: (i) a self-resistance of the conductor material, (ii) contact resistance between material of the element and soil and (iii) soil resistivity itself. Thus, the total resistance that resists to the current which leaks from the element to earth can be presented as:

$\mathrm{R}_{\text {hor(ver) }}=\mathrm{R}_{\text {me }}+\mathrm{R}_{\text {cont }}+\mathrm{R}_{\text {soil }}$.

However, the first two elements $\left(R_{\mathrm{me}}\right.$ and $\left.R_{\text {cont }}\right)$ have very small values and often can be neglected.

The resistance of the vertical and horizontal elements in the soil can be calculated as

$R_{v e r}=\frac{\rho_{e v}}{2 \pi \cdot l_{v e r}} \cdot\left(\ln \frac{2 l_{v e r}}{d_{v e r}}+0.5 \ln \frac{4 l_{v e r}+7 . t}{l_{v e r}+7 . t}\right)$

Where, $\rho_{e . v}-$ equivalent resistance of earth for the vertical elements, $\Omega \mathrm{m} ; t$ - depth of the grounding grid; $l_{v e r}$ - length of the vertical element; $d_{v e r}$ - diameter of the vertical element

$R_{\text {hor }}=\frac{\rho_{e . h}}{2 \pi \cdot l_{\text {hor }}} \cdot \ln \frac{l_{\text {hor }}^{2}}{t \cdot d_{\text {hor }}}$

Where, $\rho_{e . h}$ - equivalent resistance of the earth for the horizontal elements, $\Omega \mathrm{m} ; l_{h o r}$-length of the horizontal element, $d_{h o r}-$ diameter of the horizontal element.

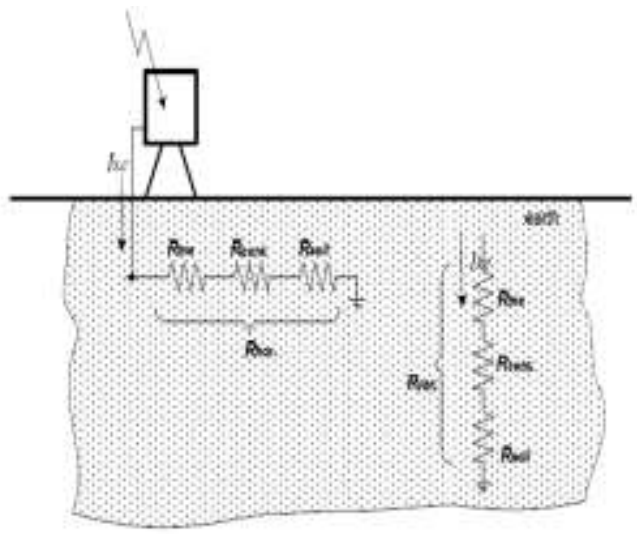

Figure 2: Equivalent scheme of the horizontal and vertical elements in the soil

The resistance of earth $R_{\text {soil }}$ depends on the resistivity of different soil stratums $\left(\rho_{1}, \rho_{2}, \rho_{3}\right.$ etc. $)$. The number of layers (stratums) can differ from one area to another depending on the soil structure.

\subsection{Sample data for test system}

This test system is carried from [B-3] rectangular grid with ground rod in IEEE std-80.the detail design data can be seen from the following table.

Table 1: Sample data for substation

\begin{tabular}{|c|c|}
\hline Fault duration, $\mathrm{tf}$ & $0.5 \mathrm{~s}$ \\
\hline Soil resistivity, $\rho$ & $400 \Omega \mathrm{m}$ \\
\hline Crushed rock resistivity, $\rho \mathrm{s}$ & $2500 \Omega \mathrm{m}$ \\
\hline Depth of grid burial,t & $0.5 \mathrm{~m}$ \\
\hline Available grounding area, A & $64 \mathrm{~m} \mathrm{x} 84 \mathrm{~m}$ \\
\hline Grid spacing, D & $7 \mathrm{~m}$ \\
\hline Ground rod length & $10 \mathrm{~m}$ for $38 \mathrm{rods}$ \\
\hline Allowable touch voltage & $838.2 \mathrm{~V}$ \\
\hline Diameter of ground rod & $0.01 \mathrm{~m}$ \\
\hline frequency & $60 \mathrm{~Hz}$ \\
\hline
\end{tabular}

By taking required data from table 1, the values of horizontal and vertical elements of the substation grounding grid can be calculated by using equation (2) and (3) in order to make a simulation model in MULTISIM. 


\subsection{Calculation of horizontal and vertical}

\section{resistance}

Case (1), is the base case and grid layout dimension is shown in figure 3. The area of the grid layout is $63 \mathrm{~m} \times 84 \mathrm{~m}$. In this case, threre are 38 vertical earth rods, each of $10 \mathrm{~m}$ long. The calculated values are, $R_{\text {hor }}=90.45 \Omega$ and $R_{\text {ver }}=52.113 \Omega$.

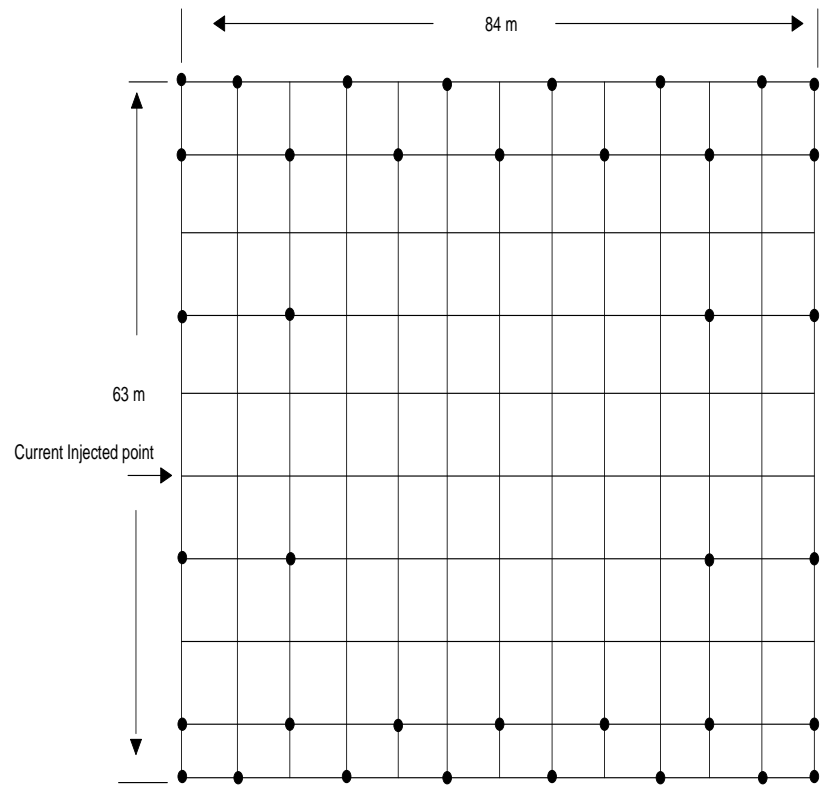

Figure 3: case (i) grid layout plan with $10 \mathrm{~m}$ x 38 rods

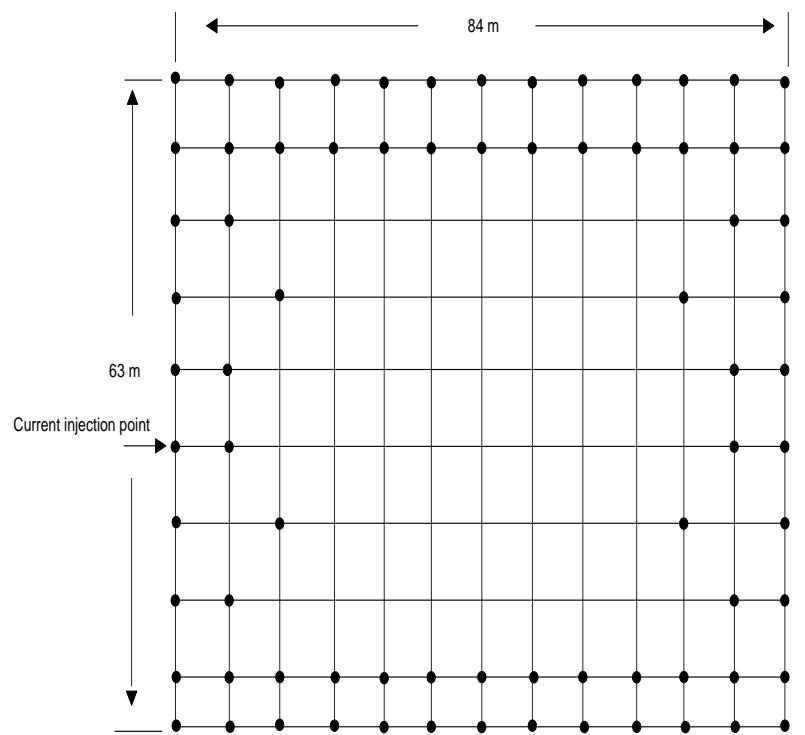

Figure 4: case (ii) grid layout plan with $5 \mathrm{~m} \mathrm{x} 76$ rods

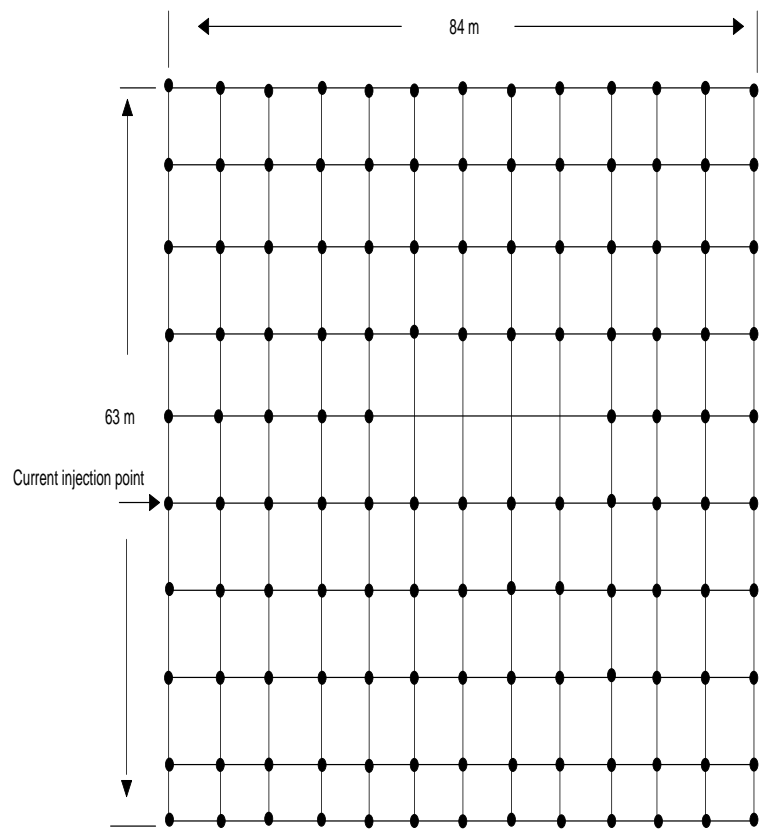

Figure 5: case (iii) grid layout plan with $3 \mathrm{~m}$ x 126 Rods

In case (ii), the value of ground rod length $10 \mathrm{~m}$ is reduced to $5 \mathrm{~m}$ while another 38 ground rods each of $5 \mathrm{~m}$ long is added to the existing elements and keeping the other parameters remain the same. So, net total of 76 vertical ground rods is introduced. In this condition, only the value of vertical element is changed to $\mathrm{R}_{\mathrm{ver}}=94.43 \Omega$. Earthing grid layout design for case (ii) is shown in figure 4.

Also in case (iii), the length of vertical ground rod is reduced to $3 \mathrm{~m}$ and the numbers of vertical earth rods are increased to total of 126 , as shown in figure 5. Other parameter are taken as the previous cases. Here, the value of the vertical earth rod for case (iii), $\mathrm{R}_{\mathrm{ver}}=144.968 \Omega$.

\section{CALCULATION OF EARTHING GRID RESISTANCE}

A good grounding system provides a low resistance to remote earth in order to minimize the GPR. For most transmission and other large substations, the ground resistance is usually about $1 \Omega$ or less. In smaller distribution substations, the usually acceptable range is from $1 \Omega$ to $5 \Omega$, depending on the local conditions. 
Sverak [B132] expanded Equation to take into account the effect of grid depth;

$R_{g}=\rho\left[\frac{1}{L_{T}}+\frac{1}{\sqrt{20 A}}\left(1+\frac{1}{1+h \sqrt{\frac{20}{A}}}\right)\right]$

Where,

$$
\begin{array}{ll}
R_{g} & \text { is the substation ground resistance in } \Omega \\
\rho & \text { is the soil resistivity in } \Omega \cdot \mathrm{m} \\
A & \text { is the area occupied by the ground grid in } \mathrm{m}^{2} \\
h & \text { is the depth of the grid in } \mathrm{m} \\
L_{T} & \text { is the total buried length of conductors in } \mathrm{m}
\end{array}
$$

When the practical data are substituted in equation, the same value of earthing grid resistance have same at $2.62 \Omega$ because case (i),(ii),(iii) have not changed total burial length of the grid and soil resistivity.

\section{CALCULATION OF MAXIMUM STEP AND MESH VOLTAGES}

\subsection{Mesh voltage $\left(E_{m}\right)$}

The mesh voltage values are obtained as a product of the geometrical factor, $K_{m}$; a corrective factor, $K_{i}$, which accounts for some of the error introduced by the assumptions made in deriving $K_{m}$; the soil resistivity, $\rho$; and the average current per unit of effective buried length of the grounding system conductor $\left(\mathrm{I}_{\mathrm{G}} / \mathrm{L}_{\mathrm{M}}\right)$

$E_{m}=\frac{\rho \cdot K_{m} \cdot K_{i} \cdot I_{G}}{L_{M}}$

The geometrical factor $K_{m}$ (Sverak [B132]), is as follows

$K_{m}=\frac{1}{2 . \pi}\left[\ln \frac{D^{2}}{16 \cdot h \cdot d}+\frac{(D+2 \cdot h)^{2}}{8 \cdot D \cdot d}-\frac{h}{4 \cdot d}\right]+\frac{K_{i i}}{K_{h}} \cdot \ln \left[\frac{8}{\pi(2 \cdot n-1)}\right]$

For grids with ground rods along the perimeter, or for grids with ground rods in the grid corners, as well as both along the perimeter and throughout the grid area,

$\mathrm{K}_{\mathrm{ii}}=1$

For grids with no ground rods or grids with only a few ground rods, none located in the corners or on the perimeter.

$$
\begin{aligned}
& K_{i i}=\frac{1}{(2 . n)^{\frac{2}{n}}} \\
& K_{h}=\sqrt{1+\frac{h}{h_{o}}}
\end{aligned}
$$

Where, $\mathrm{h}$ is actual grid depth

$\mathrm{h}_{\mathrm{o}}$ is grid reference depth $(1 \mathrm{~m})$

Using four grid shape components developed in Thapar, Gerez, Balakrishnan, and Blank [B144], the effective number of parallel conductors in a given grid, $n$, can be made applicable to rectangular or irregularly shaped grids that represent the number of parallel conductors of an equivalent rectangular grid.

$n=n_{a} \cdot n_{b} \cdot n_{c} \cdot n_{d}$

Where, $n_{a}=\frac{2 \cdot L_{c}}{L_{p}}$

$$
\begin{aligned}
& n_{b}=1 \text { for square grids } \\
& n_{c}=1 \text { for square and rectangular grids } \\
& n_{d}=1 \text { for square, rectangular and 1-shaped grids }
\end{aligned}
$$

Otherwise,

$n_{b}=\sqrt{\frac{L_{p}}{4 \cdot \sqrt{A}}}$

$n_{c}=\left[\frac{L_{x} L_{y}}{A}\right]^{\frac{0.7 \cdot A}{L_{x} \cdot L_{y}}}$

$n_{d}=\frac{D_{m}}{\sqrt{L_{x}^{2}+L_{y}^{2}}}$

Where, $L_{C}$ is the total length of the conductor in the horizontal grid in $\mathrm{m}, L_{p}$ is the peripheral length of the grid in $\mathrm{m}, A$ is the area of the grid in $\mathrm{m}^{2}, L_{x}$ is the maximum length of the grid in the $\mathrm{x}$ direction in $\mathrm{m}, L_{y}$ is the maximum length of the grid in the y direction in $\mathrm{m}, D_{m}$ is the maximum distance between any two points on the grid in $\mathrm{m}$ and $D, h$, and $d$ are defined in Table 1.

The irregularity factor, $K i$, used in conjunction with the above defined $n$ is:

$K_{i}=0.6440 .148 \cdot n$

For grids with no ground rods, or grids with only a few ground rods scattered throughout the grid, but none located in the corners or along the perimeter of the grid, the effective buried length, $L_{M}$, is

$L_{M}=L_{C}+L_{R}$ 
Where, $L_{R}$ is the total length of all ground rods in $\mathrm{m}$

For grids with ground rods in the corners, as well as along the perimeter and throughout the grid, the effective buried length,

$L_{M}=L_{C}+\left[1.55+1.22\left(\frac{L_{r}}{\sqrt{L_{x}^{2}+L_{y}^{2}}}\right)\right] L_{R}$

Where, $L_{r} \quad$ is the length of each ground rod in $\mathrm{m}$.

The mutual impedance among elements in the grid can be presented by multiplication factor " $F$ " from [3];

$F=1+\frac{\left(2+\frac{N}{4}\right) \cdot \frac{l}{d_{s}}}{\ln \left(\frac{4 l}{a}\right)-1}$

Where, $N$ - the total number of rods in rod bed, $d_{s}-$ the smallest distance between the adjacent rods, $\mathrm{m}, \quad l-$ the length of each conductor, $a$-radius of the conductor.

This $F$ factor increases the resistance of each element of the grid or finally the value of voltage on the grid. It happens because electromagnetic fields of all elements of the grid influence on each other due to the small distance between them as shown in figure 6 . Thus, it artificially increases the value of resistance of each element.



Figure 6: Influence of the element on each other [4].

\subsection{Step voltage (Es)}

The step voltage values are obtained as a product of the geometrical factor, $K_{s}$; the corrective factor, $K_{i}$; the soil resistivity, $\rho$; and the average current per unit of buried length of grounding system conductor $\left(I_{G} / L_{S}\right)$.
$E_{S}=\frac{\rho \cdot K_{S} \cdot K_{i} \cdot I_{G}}{L_{S}}$

For grids with or without ground rods, the effective buried conductor length, $L_{s}$, is

$L_{S}=0.75 \cdot L_{C}+0.85 \cdot L_{R}$

The maximum step voltage is assumed to occur over a distance of $1 \mathrm{~m}$, beginning at and extending outside of the perimeter conductor at the angle bisecting the most extreme corner of the grid. For the usual burial depth of $0.25 \mathrm{~m}<h<2.5 \mathrm{~m}$ (Sverak [B132]), $K_{s}$ is

$$
K_{S}=\frac{1}{\pi}\left[\frac{1}{2 . h}+\frac{1}{D+h}+\frac{1}{D}\left(1-0.5^{n-2}\right)\right]
$$

\subsection{Performance Analysis of $E_{m}$ and $E_{s}$}

The performance of actual touch and step voltage depend on the variation of the parameters such as grid depth (h), grid area (A), diameters and total length of the buried conductors, soil resistivity $(\rho)$ and so on. For existing substation, enhancement of actual touch and step voltage can only be obtained by the variation of length and number of ground rods. After calculating the horizontal and vertical resistances of the grounding grids, the simulation is carried out by injecting the defined fault current level. From simulation result of the MULTISIM, ground potential rise (GPR) at the point of injection is taken as the product value of two parameters (i.e., pxIg) in the network and inserted it into the calculation of actual step and touch voltages equation. Table 2 shows measured GPR values for all cases under uniform soil of $400 \Omega \mathrm{m}$ resistivity and various injected current levels. The values of GPR for case (ii) are $41.21 \%$ less than that of case (i) and $14.06 \%$ less than case (iii) respectively for all current injected values. In normal condition, the allowable touch voltage for substation is $838.2 \mathrm{~V}$. But, during fault condition, the actual touch voltages for every case become over the allowable limit at a certain injected current level. The three injected current levels of case (i), (ii) and (iii) that make the actual touch voltages over the allowable limit are 9kA, 14kA and $12 \mathrm{kA}$ respectively. 
Table (2): Ground potential rise (GPR) at injection point

\begin{tabular}{|c|c|c|c|}
\hline $\begin{array}{c}\text { Injected } \\
\text { current (A) }\end{array}$ & $\begin{array}{c}\text { Case (i) } \\
\text { GPR (V) }\end{array}$ & $\begin{array}{c}\text { Case(ii) } \\
\text { GPR (V) }\end{array}$ & $\begin{array}{c}\text { Case (iii) } \\
\text { GPR (V) }\end{array}$ \\
\hline 1000 & $36.4 \mathrm{kV}$ & $21.4 \mathrm{kV}$ & $24.9 \mathrm{kV}$ \\
\hline 2000 & $72.7 \mathrm{kV}$ & $42.8 \mathrm{kV}$ & $49.8 \mathrm{kV}$ \\
\hline 3000 & $109 \mathrm{kV}$ & $64.2 \mathrm{kV}$ & $74.7 \mathrm{kV}$ \\
\hline 4000 & $145 \mathrm{kV}$ & $85.6 \mathrm{kV}$ & $99.6 \mathrm{kV}$ \\
\hline 5000 & $182 \mathrm{kV}$ & $107 \mathrm{kV}$ & $125 \mathrm{kV}$ \\
\hline 6000 & $218 \mathrm{kV}$ & $128 \mathrm{kV}$ & $149 \mathrm{kV}$ \\
\hline 7000 & $255 \mathrm{kV}$ & $150 \mathrm{kV}$ & $174 \mathrm{kV}$ \\
\hline 8000 & $291 \mathrm{kV}$ & $171 \mathrm{kV}$ & $199 \mathrm{kV}$ \\
\hline 9000 & $327 \mathrm{kV}$ & $193 \mathrm{kV}$ & $224 \mathrm{kV}$ \\
\hline 10000 & $364 \mathrm{kV}$ & $214 \mathrm{kV}$ & $249 \mathrm{kV}$ \\
\hline 11000 & $400 \mathrm{kV}$ & $235 \mathrm{kV}$ & $274 \mathrm{kV}$ \\
\hline 12000 & $436 \mathrm{kV}$ & $257 \mathrm{kV}$ & $299 \mathrm{kV}$ \\
\hline 13000 & $473 \mathrm{kV}$ & $278 \mathrm{kV}$ & $324 \mathrm{kV}$ \\
\hline 14000 & $509 \mathrm{kV}$ & $300 \mathrm{kV}$ & $349 \mathrm{kV}$ \\
\hline 15000 & $546 \mathrm{kV}$ & $321 \mathrm{kV}$ & $374 \mathrm{kV}$ \\
\hline
\end{tabular}



Figure 7: Variation of ground potential rise according to earthing grid design

The actual mesh and step voltages can be calculated by using equation (4) and (16) for this power plant. The mutual impedance among elements in the grid can be presented by multiplication factor " $F$ " from [3]. In [2] multiplication of $\rho \times I_{g}$ is voltage at the node of the grid. So by using the values from Table (2). So, these calculated results are as follows:
Table (3) Actual mesh voltage at current injection point of the substation earthing grid

\begin{tabular}{|c|c|c|c|}
\hline $\begin{array}{c}\text { Injected } \\
\text { current } \\
\text { (A) }\end{array}$ & $\begin{array}{c}\text { Case (i) } \\
\text { Mesh Voltage } \\
(\mathrm{V})\end{array}$ & $\begin{array}{c}\text { Case (ii) } \\
\text { Mesh Voltage } \\
\text { (V) }\end{array}$ & $\begin{array}{c}\text { Case (iii) } \\
\text { Mesh } \\
\text { Voltage } \\
\text { (V) }\end{array}$ \\
\hline 1000 & 99.408 & 59.877 & 72.310 \\
\hline 2000 & 198.544 & 119.754 & 144.619 \\
\hline 3000 & 297.679 & 179.632 & 216.929 \\
\hline 4000 & 395.995 & 239.509 & 289.238 \\
\hline 5000 & 497.042 & 299.386 & 363 \\
\hline 6000 & 595.358 & 358.144 & 432.696 \\
\hline 7000 & 696.405 & 419.700 & 505.296 \\
\hline 8000 & 794.721 & 478.458 & 577.896 \\
\hline 9000 & 893.073 & 540.014 & 650.496 \\
\hline 10000 & 994.084 & 598.772 & 723.096 \\
\hline 11000 & 1092.400 & 657.530 & 795.696 \\
\hline 12000 & 1190.716 & 719.086 & 868.296 \\
\hline 13000 & 1291.763 & 777.844 & 940.896 \\
\hline 14000 & 1390.079 & 839.400 & 1013.496 \\
\hline 15000 & 1491.126 & 898.158 & 1086.096 \\
\hline
\end{tabular}

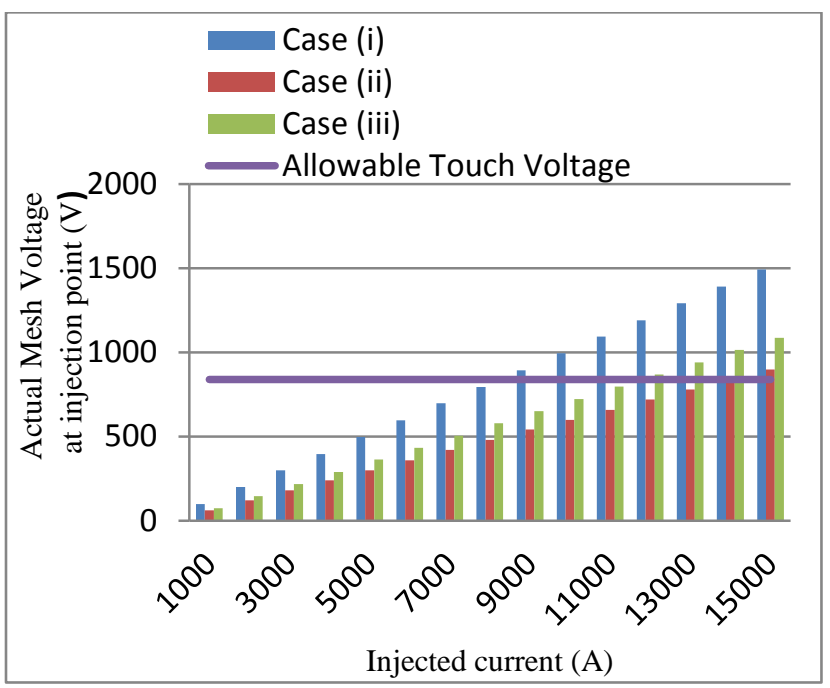

Figure 8: Actual Mesh Voltage performance of three earthing grid designs for a power plant

According to figure 8 , the actual mesh voltage of case(ii) is within allowable touch potential up to $13000 \mathrm{~A}$ of injection, but case (iii) can safe up to11000 A and case(i) can only safe to 8000A. 
Table (4): Actual Step Voltage at current injection point of sample earthing grid for a substation

\begin{tabular}{|c|c|c|c|}
\hline $\begin{array}{c}\text { Injected } \\
\text { current (A) }\end{array}$ & $\begin{array}{c}\text { Case (i) } \\
\text { Step Voltage } \\
(\mathrm{V})\end{array}$ & $\begin{array}{c}\text { Case (ii) } \\
\text { Step Voltage } \\
\text { (V) }\end{array}$ & $\begin{array}{c}\text { Case (iii) } \\
\text { Step } \\
\text { Voltage (V) }\end{array}$ \\
\hline 1000 & 76.658 & 45.710 & 54.979 \\
\hline 2000 & 153.106 & 91.421 & 109.958 \\
\hline 3000 & 229.554 & 137.131 & 164.938 \\
\hline 4000 & 305.370 & 182.842 & 219.917 \\
\hline 5000 & 383.292 & 228.552 & 276.000 \\
\hline 6000 & 459.108 & 273.408 & 328.992 \\
\hline 7000 & 537.030 & 320.400 & 384.192 \\
\hline 8000 & 612.846 & 365.256 & 439.392 \\
\hline 9000 & 688.662 & 412.248 & 494.592 \\
\hline 10000 & 766.584 & 457.104 & 549.792 \\
\hline 11000 & 842.400 & 501.960 & 604.992 \\
\hline 12000 & 918.216 & 548.952 & 660.192 \\
\hline 13000 & 996.138 & 593.808 & 715.392 \\
\hline 14000 & 1071.954 & 640.800 & 770.592 \\
\hline 15000 & 1149.876 & 685.656 & 825.792 \\
\hline
\end{tabular}

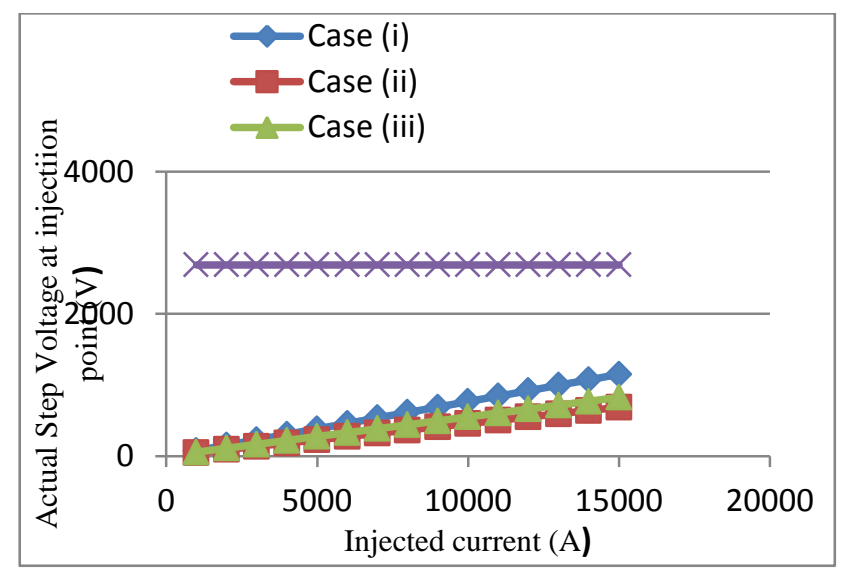

Figure 9: Actual step Voltage Variation at the injection point for three earthing grid design of a substation

\section{CONCLUSIONS}

This paper has presented performance analysis of actual step and mesh voltage of substation grounding system with the variation of length and number of vertical earth rod. The study involved a simulation with MULTISIM to an IEEE test system for three different cases. It should be noted that earth grid resistance for three cases are equal because diameter of vertical earth rod and total burial length of the grid for all cases have not changed and it is under uniform soil resistivity. The values of GPR for case (ii) is $41.21 \%$ less than GPR of case (i). Moreover, case (ii) GPR is also $14.06 \%$ less than GPR of case (iii) for all current injected values. This shows that providing the more branches to flow the fault currents (i.e., adding more vertical earth rods) means the less potential rise in step and mesh voltage and GPR except for the case that the vertical earth rods resistance is greater than the horizontal elements resistance. In case (i), 9kA of injected fault current level makes the system actual touch voltage over the allowable limit while it is $12 \mathrm{kA}$ in case (iii). Since $14 \mathrm{kA}$ of injected fault current level can only make the system actual touch voltage over the allowable limit in case (ii), it can be seen that case (ii) only can withstand the highest injected current level among three cases. Thus case (ii) is the safest design among three alternatives. This paper covers only for the single layer of soil or uniform soil resistivity. For two layer soil model or non-uniform soil, the calculation of touch and step voltage performance should be considered the sign and value of reflection factor coefficient " $\mathrm{k}$ " according to upper layer and lower layer resistivity and also the depth of the top layer, ' $h$ '.

\section{ACKNOWLEDGMENTS}

The author would like to express grateful thanks to her supervisor Dr. Yan Aung Oo, Associate Professor and to all her teachers from Department of Electrical Power Engineering, Mandalay Technological University for their encouragement and helpful suggestions. And the author also would like to express her gratitude to her parents for their support and encouragement.

\section{REFERENCE}

IEEE Std.80-2000:'IEEE Guide for Safety in AC Substation Grounding”. The Institute of Electrical and Electronic Engineers, New York, 2000.

[2] Li, Z., Chen, W., Fan, J., Lu, J. “A Novel Mathematical Modeling of Grounding System Buried in Multilayer Earth". IEEE Transactions on Power Delivery, v. 21(3), 2006. 
El Sherbiny M., "Simple Formulas for Calculating the

Grounding Resistance of Rodbed Buried in Non-

Uniform Soil". Proceedings of the 37th Midwest

Symposium on Circuits and Systems University of

Waterloo, Waterlo, Ontario, Canada N2L 3Gl, 1954,

pp. 1281-1284.

[4] Yury Chikarov., "Safety Parameters of Grounding

Devices at an Electric Power Plant". Department of

Electrical and Electronic Engineering, Auckland

University of Technology, Auckland, New Zealand. 